\title{
ANTI-INFLAMMATORY ACTIVITY OF MANILKARA ZAPOTA LEAF EXTRACT
}

\section{KAMALAKARARAO KONUKU $\mathrm{a}^{*}$, KRISHNA CHAITHANYA KARRI b, VELLIYUR KANNIAPPAN GOPALAKRISHNAN ZENEBE HAGOS ${ }^{b}$, HAFTOM KEBEDEc, TENTU KASI NAIDUd, PATRICIA PONCE NOYOLA ${ }^{\mathrm{e}}$, JOHN DOGULAS PALLETI, GOVINDA RAO DUDDUKURI ${ }^{\mathrm{f}}$}

\begin{abstract}
aDepartment of Biochemistry, Aditya Degree and PG College, Kakinada, Andhra Pradesh, India, bDepartment of Chemistry, College of Natural and Computational Sciences Aksum University, Axum, Ethiopia, cDepartment of Biology, College of Natural and Computational Sciences Aksum University, Axum, Ethiopia, dDepartment of Medical Laboratory Sciences, School of Health Sciences, Dilla University, Dilla, Ethiopia, eDepartment of Life Sciences, University of Guanajuato, Mexico, fDept of Biochemistry and Molecular Biology, School of Biological Science, Central University of Kerala, India

Email: dr.kamalakararaokonuku@yahoo.com
\end{abstract}

Received: 15 Feb 2017, Revised and Accepted: 10 May 2017

\begin{abstract}
Objective: Manilkara zapota is a medicinal plant which is native to Mexico and Central America, and widely distributed in India. Various parts of this plant are traditionally used for treatment of several diseases, including inflammation-associated ailments. The main aim of the present study is to evaluate the anti-inflammatory potential of ethyl acetate and methanolic extracts of M. zapota leaf.
\end{abstract}

Methods: In vitro secretary phospholipase $\mathrm{A}_{2}\left(\mathrm{PLA}_{2}\right)$ and 5-Lipoxygenase (5-LOX) assays and In vivo studies using carrageenan induced rat paw edema model were performed to assess the anti-inflammatory activity of M. zapota leaf extracts.

Results: In vitro studies suggest that M. zapota leaf extracts exhibited significant ${ }_{s} \mathrm{PLA}_{2}$ and 5-LOX inhibitory activities. In in vivo studies $M$. zapota leaf extracts showed dose dependent inhibition of carrageenan induced paw edema in rats. The anti-inflammatory activity of ethyl acetate leaf extract was superior to methanolic extract.

Conclusion: This study concluded that ethyl acetate leaf extract of M. zapota exhibited significant anti-inflammatory activity and warranted further investigation to isolate and identify the components.

Keywords: Manilkara zapota, COX-2, Phospholipase A2, TNF- $\alpha$, IL-1 $\beta$,IL-6, IFN- $\gamma$

(C) 2017 The Authors. Published by Innovare Academic Sciences Pvt Ltd. This is an open access article under the CC BY license (http://creativecommons.org/licenses/by/4.0/) DOI: http://dx.doi.org/10.22159/ijcpr.2017v9i4.20977

\section{INTRODUCTION}

The immune system has developed gradually as a unique complex network that defends the host body from both infectious and noninfectious foreign substances. Malfunctioning of the immune network either innate or adaptive branches, leads to chronic inflammatory diseases such as inflammatory bowel disorders, arthritis, asthma, neurodegenerative ailments and autoimmune diseases. Inflammation is a vital response of vascular tissues to infectious and non-infectious agents, both exogenous and endogenous inflammatory inducers such as lipopolysaccharides (LPS), proinflammatory cytokines such as Tumor Necrosis Factor (TNF- $\alpha$ ), Interleukin-1 $\beta$ (IL-1 $\beta$ ),Interleukin-6 (IL-6) and Interferon- $\gamma$ (IFN- $\gamma$ ) stimulates inflammatory macrophages $\mathrm{M} 1$, which elevate inflammatory mediators such as prostaglandin $\mathrm{E}_{2}$ $\left(\mathrm{PGE}_{2}\right)$ and leukotrienes (LT-4) and nitrous oxide (NO) by cyclooxygenase-2 (COX-2), 5-lipoxygenase (5-LOX) and inducible nitric oxide synthase (iNOS) [1]. Nuclear factor kappa B (NF-кB) plays a central role in the up-regulation of inflammatory pathways. Proinflammatory cytokines such as TNF- $\alpha$ and IL-1 $\beta$ act syngertically induce archidonic acid dependent and independent inflammatory pathways [2]. Inflammatory response leads to a cascade activation of NF$\kappa \mathrm{B}$ and signal transducer activator of transcription 3 (STAT3) controls stress response. TNF- $\alpha$, IL- $1 \beta$ play a vital role in ROS and RNS induced inflammation [3]. Both steroidal and non-steroidal anti-inflammatory drugs are used for treatment of inflammatory diseases [4] though these drugs have potent anti-inflammatory activity, long term administration is required for treatment of chronic diseases. Furthermore, these antiinflammatory drugs have several serious side-effects on organ functions [5]. Therefore, naturally occurring anti-inflammatory agents with a high therapeutic index and less side-effects are required as substitutes for synthetic anti-inflammatory drugs.

Manilkara zapota (Sapotaceae) and its different parts have been traditionally used for medicinal purpose. The acetone extract of $M$. zapota leaves has shown significant antioxidant activity [6]. Petroleum ether and ethanolic leaf extracts of $M$. zapota were reported to have analgesic activity. The ethanolic extract of $M$. zapota possesses significant anti-arthritic activity [7]. It is likewise reported that ethyl acetate and methanolic extract of leaves of $M$. zapota shown significant inhibition of paw edema in rats. The present work deals with evaluation of anti-inflammatory activity of both ethyl acetate and methanol leaf extracts by in vitro assays such as $\mathrm{SPLA}_{2}$ inhibitory assay, 5-lipoxygenase inhibitory assay and in vivo anti-inflammatory carrageenan induced paw edema model.

\section{MATERIALS AND METHODS}

\section{Plant material collection}

Fresh leaf material of M. zapota plant was collected from Vizag steel plant area, Visakhapatnam district, Andhra Pradesh during month of May 2011. Plant leaf material was authenticated by Dr. S. B. Padal, Associate Professor, Department of Botany, Andhra University. A voucher specimen (Accession Number AU (BDH) 21913) of this plant was deposited in Botany department Herbarium, Andhra University.

Preparation of methanol/ethyl acetate leaf extract

Fresh leaves of Manilkarazapota were collected and shade dried. Further, dried leaves were pulverized into powder and used in extract preparation.

Approximately 500 grams of dried powder was extracted with solvent methanol/ethyl acetate by a hot percolation method using a Soxhlet apparatus. The obtained extracts were Rota-vaporized to obtain a crude methanol leaf extract weighing about 25 and 35 grams. The methanol and ethyl acetate extracts were used to assess their anti-inflamnmatory activity using in vitro and in vivo methods. 


\section{In vitro phospholipase $\mathrm{A}_{2}$ assay}

$\mathrm{PLA}_{2}$ assay was performed using sPLA $\mathrm{A}_{2}$ enzyme inhibitory screening kit as per instructions of manufacturer (Cayman Chemical, Ann Arbor, Michigan, USA). The reaction mixture was contained $10 \mu \mathrm{l}$ of $\mathrm{PLA}_{2}, 25,50$ and $100 \mu \mathrm{g} / \mathrm{ml}$ of ethyl acetate and methanol plant extracts, respectively in test wells, $200 \mu \mathrm{l}$ substrates and incubated for $15 \mathrm{~min}$. Further, $10 \mu \mathrm{l}$ of 5, $5^{\prime}$-dithio-bi's-(2-nitrobenzoic acid) (DTNB) was added to develop color and read at a wavelength of 415 $\mathrm{nm}$. After hydrolysis of the thioester bond at the $s n-2$ position of diheptanoyl Thio-PC (substrate) by PLA, the released free thiols were detected using DTNB, which has an absorbance at $415 \mathrm{NM}$. The control wells contain only PLA $\mathrm{P}_{2}$ substrate and DTNB. Thioetheramide-PC was used as positive control. The percent inhibition of enzyme activity was calculated using below formula:

Porcentagsinhibition - $\left(\frac{\text { Absorbance of contral - Absorbance of test }}{\text { Ahiarhnce of contral }}\right) \times 100$

\section{Lipoxygenase assay}

5-LOX inhibitory assay was performed by using UV kinetic method $[8,9]$. This method was performed by using an assay mixture consisting $3 \mathrm{ml}$ of $50 \mathrm{mM}^{*}$ phosphate buffer $\mathrm{pH}$ 6.3, along with $10 \mu \mathrm{l}$ of $80 \mathrm{mM}^{*}$ of linoleic acid and potato 5-LOX enzymes. This assay solution was kept in ice and measured the enzyme activity throughout the experiment for every two minutes at $234 \mathrm{NM}$ in UV visible spectrophotometer. The 5-LOX inhibitory activity of $M$. zapota methanol and ethyl acetate leaf extracts was tested at different concentrations viz., 5, 10,15 and $25 \mu \mathrm{g} / \mathrm{ml}$. The activity of 5-Lipoxygenase was compared with the standard positive control Quercetin. (Vendor, city, country)

The percent inhibition of 5-lipoxygenase inhibitory activity of plant extracts was calculated by using a formula.

Percentagethinbuton $=\left(\frac{\text { Absorbanes of eontroi Absorbance of tsst }}{\text { Absorbance of control }}\right) \times 100$

\section{In vivo methods}

Carrageenan-induced hind paw edema in rats (acute inflammation model)

Carrageenan-induced paw edema model, developed by [10] the most widely used for the evaluation of anti-inflammatory activity. Male Wistar albino rats weighing 150-200 g were obtained from M/s
Mahavir Enterprises (Hyderabad, Telangana, India). The animals were housed under standard conditions (Temperature of $22 \pm 100 \mathrm{C}$ with an alternating $12 \mathrm{~h}$ light-dark cycle and relative humidity of $60 \pm 5 \%$. The animals were fed with standard laboratory diet, which was purchased from M/s Rayans Biotechnology Pvt. Ltd. (Hyderabad, Telangana, India). During the experiment, the rats were allowed to have access to water and food ad libitum. Animal experiments were conducted according to CPCSEA guidelines. The animal experimental protocol was approved by the Institutional Animal Ethical Committee (IAEC) of GITAM University (IAEC no. 517/IAEC/2012). The animals were divided into four groups $(n=6)$. The first group was given normal saline by gastric incubation. The second and third groups (200 and $400 \mathrm{mg} /$ kilogram body weight) received the ethyl acetate and methanol

M. zapota leaf extracts for $10 \mathrm{~d}$ and the fourth group received diclofenac sodium as a standard (10 milligram/kilogram body weight). The paw volume was measured plethysommetrically (UgoBasile, Italy) at $0 \mathrm{~h}, 1 \mathrm{~h}, 2 \mathrm{~h}, 3 \mathrm{~h}, 4 \mathrm{~h}$, and $5 \mathrm{~h}$ after the injection of carrageenan. The percentage of inhibition of paw volume of treated groups was calculated by comparing with a mean paw volume of the control group.

$$
\text { Percentageinhibition }=\left(\frac{\text { Controlpawvolume }- \text { Testpawvolume }}{\text { Controlpawvolume }}\right) \times 100
$$

\section{Statistical analysis}

Experimental results are expressed as mean \pm SEM A P-Value less than 0.05 represents significant difference compared with control group by Students $t$-test $(n=3-6)$

\section{RESULTS}

M. zapota ethyl acetate and methanol leaf extracts on PLA activity in vitro

Various doses $(25,50$ and $100 \mu \mathrm{g} / \mathrm{ml})$ of Ethyl acetate and methanol leaf extracts of $M$. zapota were evaluated for PLA 2 inhibitory activity. A significant inhibition of $\mathrm{PLA}_{2}$ was found with ethyl acetate extract when compared to methanol extract. As shown in [fig. 1] a dose dependent inhibition of $\mathrm{PLA}_{2}$ activity was observed with the doses tested, indicating the uniformity of anti $\mathrm{PLA}_{2}$ activity. Further, the $\mathrm{IC}_{50}$ of both ethyl acetate and methanol extracts was determined and found to be $122 \mu \mathrm{g} / \mathrm{ml}$ and $172.1 \mu \mathrm{g} / \mathrm{ml}$ respectively. Etheramide-PC was employed as positive control whose $\mathrm{IC}_{50}$ was $7.66 \mu \mathrm{g} / \mathrm{ml}$ respectively.

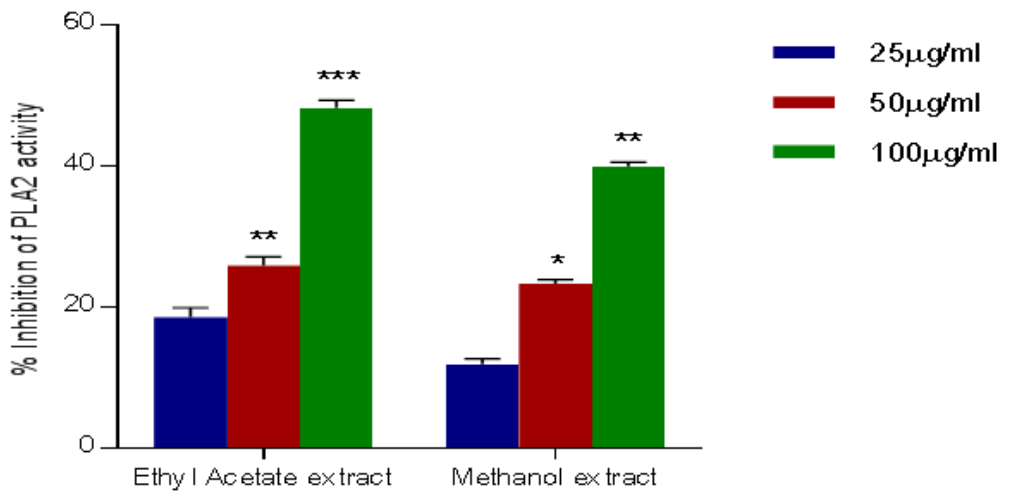

Concentrations in $\mu g^{\prime} / \mathrm{ml}$

Fig. 1: Inhibitory effect of Manilkara zapota ethyl acetate and methanol leaf extracts on

\section{M. zapota ethyl acetate and methanol leaf extracts exert inhibition of 5-LOX activity: In vitro}

5-LOX inhibitory activity of $M$. zapota has been evaluated by a UV kinetic method. The 5-LOX inhibitory activity of M. zapota ethyl acetate and methanol leaf extracts was performed with various doses viz., 5, 10, 15, 25 $\mathrm{g} / \mathrm{ml}$. As shown in fig. 2 and 3 a dose dependent inhibition of 5-LOX activity of ethyl acetate and methanol leaf extract was observed. M. zapota leaf ethyl acetate and methanol extracts shown significant 5-LOX inhibitory activity with $\mathrm{IC}_{50}$ of $15.85 \mu \mathrm{g} / \mathrm{ml}$ for ethyl acetate extract and $33.24 \mu \mathrm{g} / \mathrm{ml}$ for methanol extract respectively. Ethyl acetate extract showed significant 5-LOX inhibitory activity than methanol extract. Quercetin was employed as positive control whose $\mathrm{IC}_{50}$ was $4.85 \mu \mathrm{g} / \mathrm{ml}$. 


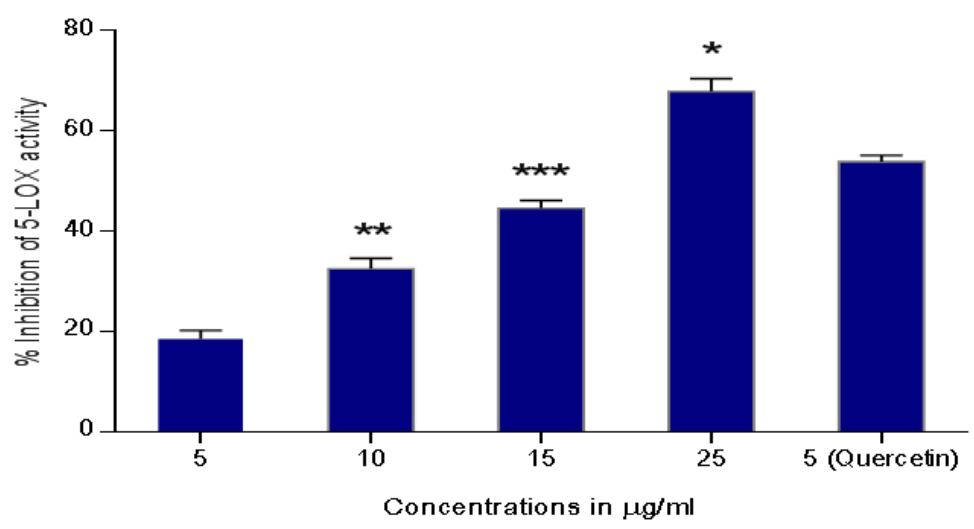

Fig. 2: Inhibitory effect of ethyl acetate leaf extract of Manilkara zapota on 5-LOX activity, Values are expressed as mean $\pm \mathrm{SEM}^{*} \mathrm{P}<0.05$, $* *$ $\mathbf{P}<0.01,{ }^{* * *} \mathbf{P}<0.001$ represents significant difference compared with control group by student's t-test $(\mathrm{n}=3)$

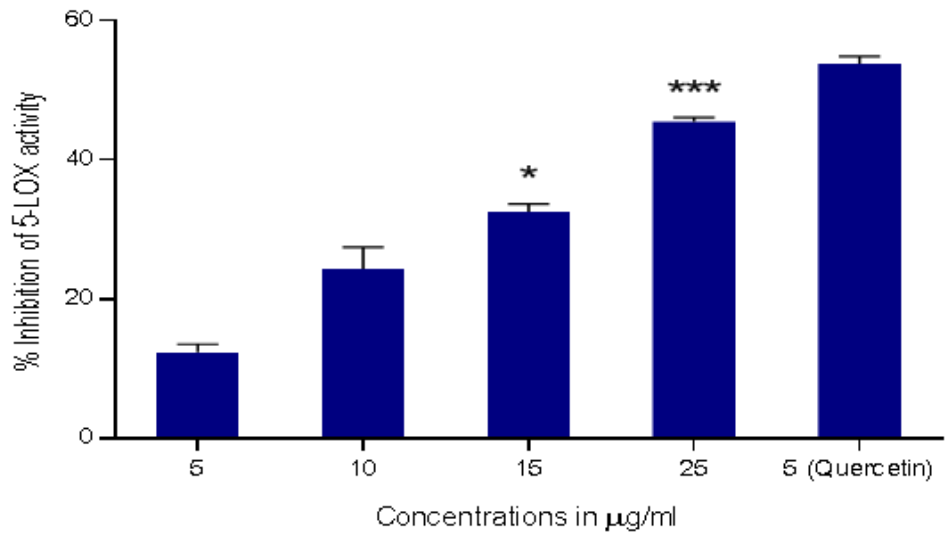

Fig. 3: Inhibitory effect of methanol leaf extract of Manilkara zapota on 5-LOX activity, values are expressed as mean \pm SEM* $P<0.05$, $* *$ $\mathbf{P}<0.01,{ }^{* * *} \mathbf{P}<0.001$ represents significant difference compared with control group by student's $\mathrm{t}$-test $(\mathrm{n}=3)$

M. zapota ethyl acetate and methanol leaf extracts display Antiinflammatory effect: in vivo

Anti-inflammatory activity of M. zapota has been evaluated by using carrageenan induced hind paw edema in rats (acute inflammatory model) developed by [10]. As shown in the fig. 4 ethyl acetate and methanol leaf extracts of M. zapota exhibited dose dependent decrease in paw edema up to 5 h. However, ethyl acetate leaf extract showed significant decrease in paw volume in late phase $4 \mathrm{hr}$ and $5 \mathrm{hr}$ when compared to methanol leaf extract as a significant decrease in paw edema was observed in late phase $4 \mathrm{~h}$ and $5 \mathrm{~h}$ when compared to methanol leaf extract as a significant inhibition of paw edema was observed in late phase $4 \mathrm{~h}$ and $5 \mathrm{~h}$. It is substantiated that inhibition of inflammation is probably due to the inhibition of inflammatory enzymes such as PLA2, COX-2 and 5-LOX.

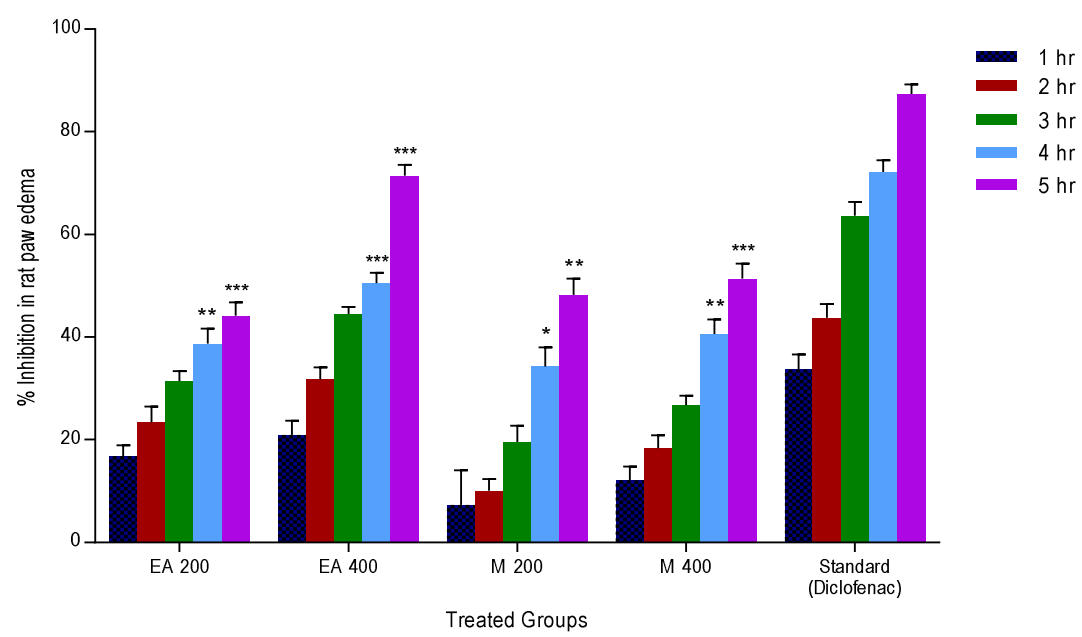

Fig. 4: Inhibition of carrageenan induced paw edema by ethyl acetate and methanol extracts, values are expressed as mean \pm SEM* $P<0.05$, ${ }^{* *} \mathbf{P}<0.01,{ }^{* * *} \mathrm{P}<0.001$ represents significant difference compared with control group by student's $\mathrm{t}$-test $(\mathrm{n}=3)$ 


\section{DISCUSSION}

Current active research is focused on herbal medicine in treating inflammation. Herbal medicines obtained from wide array of plant extracts are in high usage to cure a wide variety of inflammatory diseases [11-13]. Side effects associated with Non Steroidal Antiinflammatory Drugs (NSAIDS) made researchers to think about alternative medicine to NSAIDS which is to be natural and free from side effects [14-16]. The significance of natural anti-inflammatory compounds raised interest in pharmacological assessment of variety of plants used in traditional medicine, this interest resulted in the scientific study of herbal drugs having lesser side effects, thus providing relief to inflammation [17-19]. Thus in the present study an effort was made to evaluate the anti-inflammatory potential of methanol and ethyl acetate leaf extracts of M. Zapota by in vivo and in vitro anti-inflammatory methods. Carrageenan induced paw edema in rats is generally used as in vivo experimental model for assessing anti edematous effect of natural compounds, and assess the role of inflammatory mediators in acute inflammation [20-23]. The carrageenan induced paw edema is broadly used to evaluate potential anti-inflammatory agents particularly non-steroidal type. The time line of edema development in carrageenan induced paw edema model in rats is commonly represented by a biphasic curve. The first phase occurs within an hour of injection and is partly due to the trauma of injection and partly due to the release of 5-HT, histamine and kinins [24-28]. The anti-inflammatory effect of $M$. zapota extract was apparent in each concentration of extracts as early as the first hour of carrageenan injection and highest inhibition was during the fifth hour. It maintained the suppression of the inhibition throughout the duration of the study. This shows that the plant extract may hamper any of all process of inflammation and acts as an anti-inflammatory agent. The anti-inflammatory potential of medicinal plants has been reported in plants Solanumnigrum [22], Phyllanthus amarus [29], Syringa patula [30], Plumeria acuminate [31] and Pistia stratiotes [32]. There are few references with respect to the anti-inflammatory activity of M. zapota. As seen in this study ethyl acetate extract of $M$. zapota especially at the high dose has an inhibitory effect on edema formation in both early and late phases of carrageen an induced rat paw edema model. The significant inhibitory activity shown by the extract of M. zapota over a period of five hours in carrageen an induced inflammation was quiet similar to that exhibited by the group treated with diclofenac sodium. Animal data is valuable for developing cost effective and successful anti-inflammatory agents. This further supports the association of reverse pharmaceutics with ayurvedic drug actions. The result of this study indicates that referring to folk literature is a helpful approach to identify plants with bioactive potentials. The tested extracts showed prospective anti-inflammatory bioactivities in in vivo and in vitro models of inflammation. The nature of these bioactive compounds and their mechanism of action were not determined and will be subject to further investigation.

In vitro anti inflammatory activity was evaluated by 5-lipoxygenase and phospholipase $A_{2}$ assays, [33-37] for 5-lipoxygenase inhibitory activity both ethyl acetate and methanol extracts were tested, among the two extracts ethyl acetate extract shown significant 5-LOX inhibitory activity when compared to methanol leaf extract. The inflammatory enzyme phospholipase A2 is well known for its capability of formation of mediators of inflammation such as prostaglandins and leukotrienes. Phospholipase A2 catalyses the conversion of phospholipid to arachidonic acid which is effectively converted to prostaglandins by cyclooxygenase, the formed prostaglandins cause inflammation [38-40]. PLA2 inhibitory activity of ethyl acetate and methanol leaf extracts were evaluated, among the two extracts ethyl acetate leaf extract shown promising PLA2 inhibitory activity when compared to methanol leaf extract.

\section{CONCLUSION}

From the results of in vitro and in vivo assays, it is concluded that the ethyl acetate extract of Manilkara zapota has been found to have shown good anti-inflammatory activity over methanolic extract, as evaluated by $\mathrm{PLA}_{2}$ assay, 5-LOX assay and in vivo carrageenan induced paw edema model. The ethyl acetate extract has shown significant $\mathrm{PLA}_{2}$ inhibitory activity with $\mathrm{IC}_{50}$ of $122.1 \mu \mathrm{g} / \mathrm{ml}$ while that of standard inhibitor Thioetheramide-PC, $7.66 \mu \mathrm{g} / \mathrm{ml}$ Similarly ethyl acetate leaf extract exhibited significant 5-LOX inhibitory activity with $\mathrm{IC}_{50}$ value of $15.85 \mu \mathrm{g} / \mathrm{ml}$ while that of standard quercetin $4.851 \mu \mathrm{g} / \mathrm{ml}$. Further, it is concluded that between PLA 2 and 5-LOX inhibitory activities of ethyl acetate extract of Manilkara zapota, 5-LOX activity is more significant than $\mathrm{PLA}_{2}$ inhibitory activity as indicated by the $\mathrm{IC}_{50}$ values.

In vivo studies in carrageen an induced acute inflammation model reveal that significant anti-inflammatory activity in terms of edema inhibition was observed with ethyl acetate leaf extract in doses tested in comparison to the standard diclofenac drug

The potential anti-inflammatory and antioxidant activities of M. zapota were found to be referable to the presence of compounds such as flavonoids, terpenoids, steroids (glycosides, cardiac glycosides).

From these in vitro and in vivo anti-inflammatory studies ethyl acetate extract of $M$. zapota showed significant anti-inflammatory activity. The anti-inflammatory activities of M. zapota extracts were found to be due to its 5-LOX and PLA2 inhibitory activity. Further studies are in progress to isolate and identify novel anti-inflammatory molecule from the ethyl acetate extract of M. zapota leaves.

\section{Financial support}

This work was partially supported by UGC-MRP. F. No.42-643/2013

\section{CONFLICT OF INTERESTS}

Declared none

\section{REFERENCES}

1. Arai K, Lee F, Miyajima A, Miyatake S, Arai N, Yokota T. Cytokines: coordinators of immune and inflammatory responses. Annu Rev Biochem 1991;59:783-836.

2. Fadok VA, Voelker DR, Campbell PA, Cohen JJ, Bratton DL, Henson PM. Exposure of phosphatidylserine on the surface of apoptotic lymphocytes triggers specific recognition and removal by macrophages. J Immunol 1992;148:2207-16.

3. Hussain SP, Harris CC. Inflammation and cancer: an ancient link with novel potentials. Int J Cancer 2007;121:2373-80.

4. Bursinos LA, Karachalios T, Poultsides L, Malizos KN. Do steroids, conventional non-steroidal anti-inflammatory drugs and selective COX-2 inhibitors adversely affected fracture healing. J Musculoskeletal Neuronal Interact 2009;1:44-52.

5. Bjarnason I, Hayllar J, Macpherson AJ, Russell AS. Side effects of non-steroidal anti-inflammatory drugs on the small and large intestine in humans. Gastroenterology 1993;104:1832-47.

6. Mital Kaneria, Sumitra Chanda. Evaluation of antioxidant and antimicrobial properties of Manilkara zapota L. (chiku) leaves by sequential soxhlet extraction method. Asian Pacific J Trop Biomed 2012;3:S1526-S1533.

7. Madan Singh, Prashant Soni, Neeraj Upmanyu, Yogesh Shivhare. In vitro anti-arthritic activity of Manilkara zapota Linn. Asian J Pharm Technol 2011;1:123-4.

8. Reddanna P, Rao MK, Reddy C. Inhibition of 5-lipoxygenase by vitamin E. FEBS Lett 1985;193:39-43.

9. Sircar JC, Schwender CF, Johnson EA. Soybean lipoxygenase inhibition by non-steroidal anti-inflammatory drugs. Prosfaglandins 98325;1:393-6.

10. Winter CA, Risley EA, Nuss GW. Carrageenan-induced oedema in the hind paw of rat as an assay for anti-inflammatory activity. Proc Soc Exp Biol Ther 1962;111:544-7.

11. Warrier PK, Nambier VPK, Raman KC. Indian Medicinal Plants: A Compendium of 500 Species; 1994. p. 2, 180.

12. Hoareau L, Da Silva EJ. Medicinal plants, a re-emerging health aid. Electronic J Biotechnol 1999;2:56-70.

13. Jones WP, Chin YW, Kinghorn AD. The role of pharmacognosy in modernmedicine and pharmacy. Curr Drug Targets 2006;7:247-64.

14. Sosa S, Balicet MJ, Arvigo R, Esposito RG, Pizza C, Altinier GA. Screening of the topical anti-inflammatory activity of some central American plants. J Ethanopharmacol 2002;8:211-5.

15. Pascucci RA. Use of nonsteroidal anti-inflammatory drugs and cyclooxygenase-2 (COX-2) inhibitors: indications and complications. J Am Osteopath Assoc 2002;102:487-9.

16. Wolfe MM, David RL. Lichtenstein: gastrointestinal toxicity of non-steroidal anti-inflammatory drugs. $\mathrm{N}$ Engl J Med 1999;340:1888-99. 
17. Hersberger M. Potential role of the lipoxygenase derived lipid mediators in atherosclerosis: leukotrienes, lipoxins and resolvins. Clin Chem Laboratory Med 2010;48:1063-73.

18. Cucurou C, Battionij P, Daniel R, Mansuy D. Peroxidase-like activity of lipoxygenase: different substrate specificity of potato 5-lipoxygenase and soybean 15-lipoxygenase and particular affinity of vitamin $\mathrm{E}$ derivatives for the 5-lipoxygenase. Biochim Biophys Acta 1991;1081:99-105.

19. Mansuy D, Cucurou C, Biatry B, Battioni JP. Soybean lipoxygenase-catalyzed oxidations by linoleic acid hydroperoxide: different reducing substrates and dehydrogenation of phenidone and BW755C. Biochem Biophysical Res Commun 1988;151:339-46.

20. Brooks RR, Carpenter JF, Jones SM, Ziegler TC, Pong SF. Carrageenan-induced acute paw inflammation model and its response to non-steroidal anti-inflammatory drugs. J Pharmacol Methods 1991;25:275-83.

21. Vinegar R, Schreiber W, Hugo R. Biphasic development of carrageenan edema on rats. J Pharmacol Exp Ther 1969; 66:96-10.

22. Ravi V, Saleem TSM, Patel SS, Raamamurthy J, Gauthaman K. Antiinflammatory effect of methanolic extract of Solanum nigrum Linn Berries. Int J Appl Res Nat Prod 2009;2:33-6.

23. Ahmadiani A, Hosseiny J, Semnanian S, Javan M, Saeedi F, Kamalinejad M, et al. Antinociceptive and anti-inflammatory effects of Eleagnus angustifolia fruit extract. J Ethnophamacol 2000;72:287-92.

24. Zainul AZ, Loo YW. Antinociceptive, anti-inflammatory and antipyretic properties of the aqueous extract of Bauhinia purpurea leaves in experimental animals. Med Princ Pract 2007;16:443-9.

25. Channa S, Dar A, Anjum S, Yaqoob M, Atta-Ur-Rahman. Antiinflammatory activity of Bacopa monniera in rodents. J Ethnopharmacol 2006;104:286-9.

26. Crunkhorn P, Meacock SCR. Mediators of the inflammation induced in the rat paw by carrageenan. Br J Pharmacol 1971;42:392.

27. Boughton-Smith NK, Deckin AM, Follenfant RL, Whittle BJ, Garland LG. Role of oxygen radicals and arachidonic acid metabolites in the reverse passive arthus reaction and carrageenan paw oedema in the rat. Br J Pharmacol 1993;110:896-902.

28. Swingle KF, Shideman FE. Phases of the inflammatory response to subcutaneous implantation of a cotton pellet and their modification by certain anti-inflammatory agents. J Pharmacol Exp Ther 1972;185:226-34

29. Mahat MA, Patil BM. Evaluation of anti-inflammatory activity of methanolic extracts of Phyllanthus amarus in experimental animal models. Indian J Pharma Sci 2007;4:33-5.
30. Desouky SK, Gamal-Eldeen AM. Cytotoxic and antiinflammatory activities of some constituents from the floral buds of Syringa patula. Pharm Biol 2009;47:872-7.

31. Gupta M, Mazumder UK, Gomathi P. Thamil Selvan V. Antiinflammatory evaluation of leaves of Plumeria acuminate. BMC Alternative Complementary Med 2006;6:36.

32. Kyei S, Koffuor GA, Boampong JN. The efficacy of aqueous and ethanolic leaf extracts of Pistia stratiotes Linn. in the management of arthritis and fever. J Med Biomed Sci 2012;1:29-37.

33. Muralidhar A, Sudhakar Babu K, Ravi Shankar T, Reddanna P, Reddy GV, Latha J. In vitro and in vivo anti inflammatory activity of Butea monosperma stem bark extract. Int J Pharm Thera 2010;1:44-51.

34. Oliver W. Inhibition of 5-Lipoxygenase product synthesis by natural compounds of plant origin. Planta Med 2007;73:133157.

35. Ding, XZ, Hennig R, Adrian TE. Lipoxygenase and cyclooxygenase metabolism: New insights in treatment and chemoprevention of pancreatic cancer. Mol Cancer 2003;2:10.

36. Balsinde J, Balboa MA, Insel PA, Dennis EA. Regulation and inhibition of phospholipase A2. Annu Rev Pharmacol Toxicol 1999;39:175-18.

37. Six DA, Dennis EA. The expanding superfamily of phospholipase A enzymes: classification and characterization. Biochim Biophys Acta 2000;1488:1-2:1-19

38. Da Silva SL, Calgarotto AK, Maso V, Damico DCS, Baldasso P, Veber CL, et al. Molecular modeling and inhibition of phospholipase A2 by polyhydroxy phenolic compounds. Eur J Med Chem 2009;44:312-21.

39. Lindahl M, Tagesson C. Selective inhibition of group II phospholipase A2 by quercetin. Inflammation 1993;17:573-82.

40. Chandra V, Jasti J, Kaur P, Betzel CH, Srinivasan A, Singh TP. First structural evidence of specific inhibition of phospholipases A2 by $\alpha$-tocopherol (Vitamin E) and its implications in inflammation: crystal structure of the complex formed between phopholipase A2 and $\alpha$-tocopherol at $1.8 \AA$ resolution. J Mol Biol 2002;320:215-22.

\section{How to cite this article}

- Kamalakararao Konuku, Krishna Chaithanya Karri, Velliyur Kanniappan Gopalakrishnan, Zenebe Hagos, Haftom Kebede, Tentu Kasi Naidu, Patricia Ponce Noyola, John Dogulas Palleti, Govinda Rao Duddukuri. Antiinflammatory activity of Manilkara zapota leaf extract. Int J Curr Pharm Res 2017;9(4):130-134. 